11

\title{
Оптические свойства трехмерных островков InGaP(As), сформированных методом замещения элементов пятой группы
}

\author{
() Н.В. Крыжановская ${ }^{1}$, А.С. Драгунова ${ }^{2}$, С.Д. Комаров ${ }^{2,3}$, А.М. Надточий ${ }^{2}$, А.Г. Гладышев ${ }^{1}$, А.В. Бабичев ${ }^{1}$, \\ А.В. Уваров ${ }^{2}$, В.В. Андрюшкин ${ }^{1}$, Д.В. Денисов ${ }^{4}$, Е.С. Колодезный ${ }^{1}$, И.И. Новиков ${ }^{1}$, \\ Л.Я. Карачинский ${ }^{1}$, А.Ю. Егоров ${ }^{4}$ \\ ${ }^{1}$ Университет ИТМО, Санкт-Петербург, Россия \\ ${ }^{2}$ Санкт-Петербургский национальный исследовательский Академический университет им. Ж.И. Алферова РАН, \\ 194021 Санкт-Петербург, Россия \\ ${ }^{3}$ Санкт-Петербургский государственный электротехнический университет „ЛЭТИ“ им. В.И. Ульянова (Ленина), \\ Санкт-Петербург, Россия \\ ${ }^{4}$ ООО „Коннектор Оптикс“, \\ 194292 Санкт-Петербург, Россия \\ e-mail: nataliakryzh@gmail.com
}

Поступила в редакцию 14.10.2020 г.

В окончательной редакции 14.10.2020 г.

Принята к публикации 30.10.2020 г.

\begin{abstract}
Методами спектроскопии фотолюминесценции (ФЛ) выполнено исследование оптических свойств трехмерных квантово-размерных островков InGaPAs, сформированных методом замещения фосфора на мышьяк в слое InGaP, осажденном на GaAs непосредственно в процессе эпитаксиального роста. Линия ФЛ сформированного массива островков лежит в диапазоне 950-1000 nm при комнатной температуре. Исследования ФЛ в диапазоне температур 78-300 К свидетельствуют о существенной неоднородности массива островков, наличии центров безызлучательной рекомбинации и транспорте носителей между островками. На спектрах возбуждения люминесценции наблюдается линия, связанная с поглощением в остаточном двумерном слое InGaPAs. Применение отжига структур позволило увеличить интенсивность ФЛ при комнатной температуре до $300 \%$ при незначительном коротковолновом сдвиге линии излучения островков, а также улучшить однородность внутри массива островков.
\end{abstract}

Ключевые слова: квантовые точки, арсенид галлия, замещение фосфора, фотолюминесценция.

DOI: $10.21883 /$ OS.2021.02.50561.263-20

\section{Введение}

В настоящее время усилия многих исследовательских групп направлены на поиск методов формирования полупроводниковых квантовых точек низкой плотности, которые могут эффективно использоваться в качестве активной среды однофотонных излучателей для таких приложений как квантовая криптография [1-3], для различных схем квантовых вычислений [4-5], а также прецизионных измерений [6,7]. Разработаны различные технологические режимы эпитаксиального роста самоорганизующихся КТ или последующего отжига структуры, позволившие уменьшить плотность КТ InAs/InP до $<10^{9} \mathrm{~cm}^{-2}$ [8], KT InAs/InGaAsP/InP (100) до $1.3 \cdot 10^{9} \mathrm{~cm}^{-2}$ [9], КТ СdТе до $10^{7}-10^{8} \mathrm{~cm}^{-2}$ [10]. Также для создания КТ низкой плотности, применяется более сложный метод формирования с использованием ростовой поверхности предустановленной морфологии (site-controlled epitaxy) $[11,12]$.

Недавно в работе [13] был предложен новый способ формирования полупроводниковых трехмерных островков при замещении фосфора на мышьяк в тонком слое InGaP (толщиной менее $3 \mathrm{~nm}$ ) с использованием подложек GaAs. В этом случае на поверхности GaAs фор- мируются трехмерные островки InGaPAs/GaAs овальной формы, низкой плотности $\left(\sim 1.3 \cdot 10^{10} \mathrm{~cm}^{-2}\right)$, вытянутые вдоль направления [1-10] и излучающие в спектральном диапазоне вблизи $1 \mu \mathrm{m}$ при комнатной температуре.

В настоящей работе выполнено детальное исследование оптических свойств полученных новых гетероструктур с трехмерными островками InGaPAs/GaAs. Исследования выполнялись с помощью спектроскопии фотолюминесценции (ФЛ) в диапазоне температур 78-300 K и при $10 \mathrm{~K}$ с помощью спектроскопии возбуждения люминесценции (СВЛ). Также исследовано влияние кратковременного отжига гетероструктур на их оптические свойства.

\section{1. Эксперимент}

Гетероструктуры были синтезированы методом молекулярно-пучковой эпитаксии на полуизолирующих подложках GaAs на установке Riber49. Структуры состояли из буферного слоя $\mathrm{GaAs}$ толщиной $100 \mathrm{~nm}$, слоя GaAs толщиной $200 \mathrm{~nm}$, ограниченного со стороны подложки и поверхности барьерными слоями AlGaAs толщиной $100 \mathrm{~nm}$. Трехмерные островки формировались 
Особенности технологических режимов формирования образцов $\mathrm{C} 1-\mathrm{C} 3$

\begin{tabular}{|c|c|c|c|}
\hline $\begin{array}{c}\text { № } \\
\text { структуры }\end{array}$ & $\begin{array}{c}\text { Толщина слоя } \\
\mathrm{InGaP,nm}\end{array}$ & $\begin{array}{c}\text { Время } \\
\text { выдержки, } \\
\text { min }\end{array}$ & $\begin{array}{c}\text { Температура } \\
\text { подложки во время } \\
\text { выдержки, }{ }^{\circ} \mathrm{C}\end{array}$ \\
\hline $\mathrm{C} 1$ & 2 & 5 & 520 \\
\hline $\mathrm{C} 2$ & 2 & $5(0.5+4.5)$ & 535 \\
\hline $\mathrm{C} 3$ & 3 & $10(0.5+9.5)$ & 535 \\
\hline
\end{tabular}

путем осаждения исходного слоя $\operatorname{InGaP}\left(\operatorname{In}_{0.49} \mathrm{Ga}_{0.51} \mathrm{P}\right.$, решеточно-согласованного по составу с GaAs) в середине слоя GaAs толщиной $200 \mathrm{~nm}$. При формировании островков поток фосфора заменялся на поток мышьяка в течение $30 \mathrm{~s}$, и затем происходила выдержка ростовой поверхности в потоке мышьяка в течение 5-10 min, во время которой происходило замещение атомов фосфора в слое InGaP на атомы мышьяка с последующим формированием слоя InGaPAs. После этого слой $\mathrm{InGaP}(\mathrm{As})$ заращивался $5 \mathrm{~nm} \mathrm{GaAs}$. Вся структура завершалась слоем GaAs толщиной $5 \mathrm{~nm}$ для предотвращения окисления.

Была изготовлена серия образцов $(\mathrm{C} 1-\mathrm{C} 3)$, отличающихся толщиной исходного слоя In $\mathrm{GaP}$, температурой подложки во время выдержки и длительностью выдержки в потоке мышьяка. Особенности технологических режимов формирования образцов представлены в таблице. В образцах $\mathrm{C} 2-\mathrm{C} 3$ после осаждения слоя $\mathrm{InGaP}$ в течение $30 \mathrm{~s}$ после смены потоков элементов пятой группы происходило повышение температуры подложки на $15^{\circ} \mathrm{C}$.

Для исследований ФЛ структур образец размещался в криостате Janis ST-500, позволяющем контролировать температуру образца в диапазоне $78-300 \mathrm{~K}$. Возбуждение ФЛ производилось YLF: $\mathrm{Nd}^{+3}$-лазером, работающим в непрерывном режиме (длина волны $527 \mathrm{~nm}$ ). Мощность лазера менялась в диапазоне $0.2-2 \mathrm{~mW}$. Детектирование сигнала ФЛ выполнялось с помощью монохроматора DK480 Spectral products и одноканального кремниевого детектора $\mathrm{Si}$ с помощью синхронного детектирования (SRS 510 „Stanford Research Systems“). Спектры возбуждения ФЛ были получены с использованием света галогеновой лампы и монохроматора МДР12. Регистрация спектров производилась при помощи одноканального Ge-детектора и монохроматора МДР-23.

\section{2. Результаты и обсуждение}

На спектрах ФЛ, полученных при комнатной температуре (рис. 1, $a$ ), наблюдаются 2 спектральные полосы, одна из которых $(\sim 872 \mathrm{~nm})$ соответствует излучению GaAs, а вторую $(950-1000 \mathrm{~nm})$ мы связываем с излучением островков InGaPAs. В структуре C1 длина волны максимума линии излучения InGaPAs островков составляет $\sim 960 \mathrm{~nm}$. Увеличение температуры подложки во время выдержки ростовой поверхности в потоке
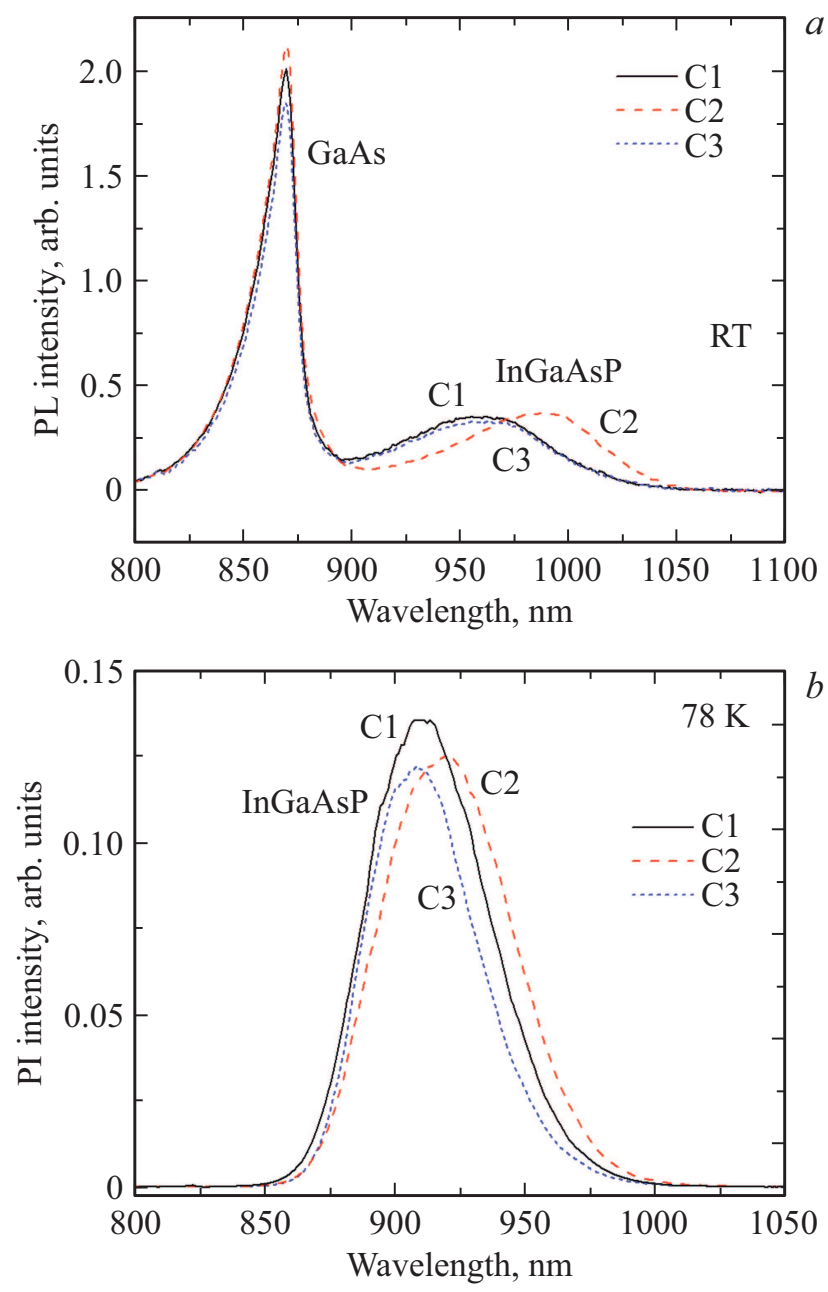

Рис. 1. Спектры ФЛ структур $\mathrm{C} 1-\mathrm{C} 3$, полученные при комнатной температуре $(a)$ и при температуре $78 \mathrm{~K}(b)$.

мышьяка привело к длинноволновому сдвигу максимума этой линии на $40 \mathrm{~nm}$ до $\sim 990 \mathrm{~nm}$ (структура С2). Увеличение времени выдержки ростовой поверхности в потоке мышьяка с 5 до $10 \mathrm{~min}$ привело к обратному коротковолновому сдвигу максимума ФЛ относительно структуры С2 (структура С3), и, таким образом, структура С3 демонстрирует самое коротковолновое излучение.

При увеличении мощности оптической накачки от $\sim 0.15$ до $1.4 \mathrm{~mW}$ (плотность оптической мощности менялась от $500 \mathrm{~W} / \mathrm{cm}^{2}$ до $4.6 \mathrm{~kW} / \mathrm{cm}^{2}$ ) наблюдается линейный рост интенсивности линии ФЛ островков (рис. 2), а также происходит коротковолновый сдвиг спектрального положения максимума этой линии, связанный с постепенным заполнением состояний более глубоких (длинноволновых) центров локализации носителей и их насыщением (вставка к рис. 2). Наименьшая величина спектрального сдвига получена для структуры C2 (16 meV), более значительный эффект заполнения состояний выражен в структуре C3 (36 meV). При увеличении оптической мощности происходит существенно более сильное возрастание интенсивности линии GaAs 


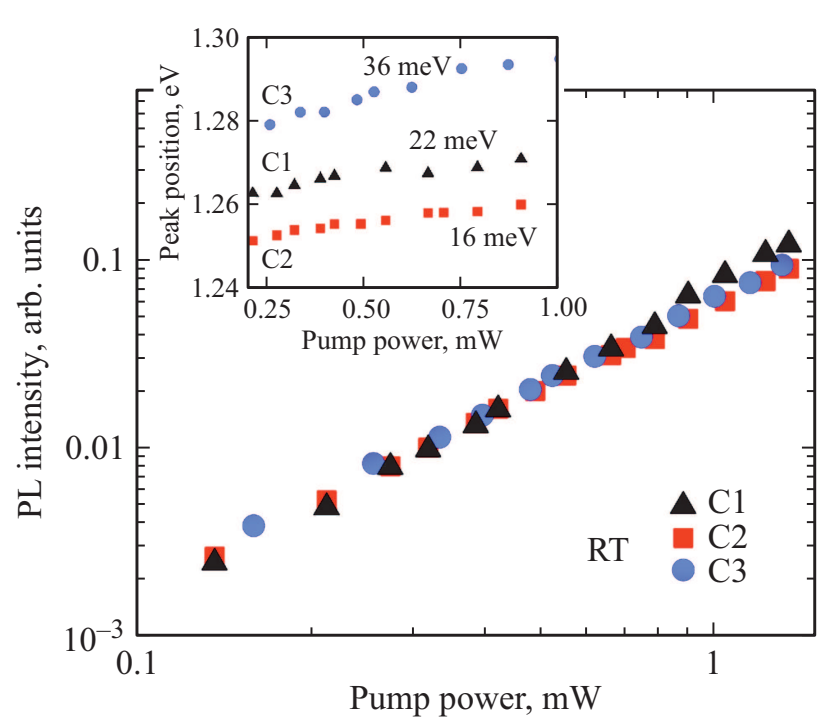

Рис. 2. Зависимость интенсивности ФЛ линии островков InGaPAs структур C1-C3 от мощности оптической накачки при комнатной температуре. Вставка: зависимость длины волны спектрального положения максимума линии островков InGaPAs от мощности оптической накачки.

по сравнению с линией излучения островков, что затрудняет анализ поведения линии излучения островков InGaPAs при более высокой мощности накачки, а также не позволяет наблюдать насыщение ее интенсивности.

При температуре $78 \mathrm{~K}$ (рис. $1, b$ ) полоса, соответствующая излучению $\mathrm{GaAs}$, практически отсутствует, наблюдается только широкая линия излучения островков InGaPAs. Такая широкая линия излучения островков InGaPAs, очевидно, обусловлена распределением массива островков по размерам или составу. Полуширина линии ФЛ островков InGaPAs составила $79 \mathrm{meV}$ для структуры $\mathrm{C} 1$, увеличение температуры подложки (структура C2) приводит к уширению линии преимущественно в сторону больших длин волн до $93 \mathrm{meV}$, возможно, за счет увеличения разброса островков по размерам за счет формирования более крупных островков или увеличения содержания As в них. Увеличение времени выдержки ростовой поверхности в потоке мышьяка до $10 \min$ (структура С3) приводит к формированию более однородного массива островков по размеру и уменьшению полуширины линии ФЛ до $74 \mathrm{meV}$.

При увеличении температуры от 78 до $300 \mathrm{~K}$ спектры ФЛ всех трех исследованных образцов демонстрируют в целом схожее поведение (рис. 3, $a$ ): наблюдается падение интегральной интенсивности ФЛ и длинноволновый сдвиг максимума ФЛ. Наименьшее значение падения интегральной интенсивности линии ФЛ островков InGaPAs было получено для наиболее длинноволновой структуры С2 и составило $~ 400$ раз. При этом на начальном участке температур $(78-120 \mathrm{~K})$ интенсивность меняется слабо, а при температурах выше $\sim 120 \mathrm{~K}$ зависимость демонстрирует монотонное падение ин- тенсивности. Зависимость полуширины линии ФЛ от температуры (рис. 3,b) также имеет два характерных участка, связанных с температурным перераспределением носителей внутри массива островков InGaPAs c различной глубиной локализации. На начальном участке температур наблюдается уменьшение полуширины линии ФЛ вследствие выброса носителей из слаболокализованных состояний и захвата их на более глубокие уровни. Дальнейшее увеличение температуры приводит к термическому выбросу носителей в островки с менее глубоким потенциалом локализации или в материал матрицы (GaAs), что приводит к уширению линии ФЛ и гашению интенсивности ФЛ вследствие безызлучательной рекомбинации на структурных дефектах. Температура, при которой наблюдается минимальное значение полуширины линии ФЛ, зависит от длины волны излучения структуры и глубины локализации носителей: перегиб наблюдается вблизи $100 \mathrm{~K}$ для структуры С3, вблизи $130 \mathrm{~K}$ для структуры С1 и вблизи $200 \mathrm{~K}$ для структуры C2.
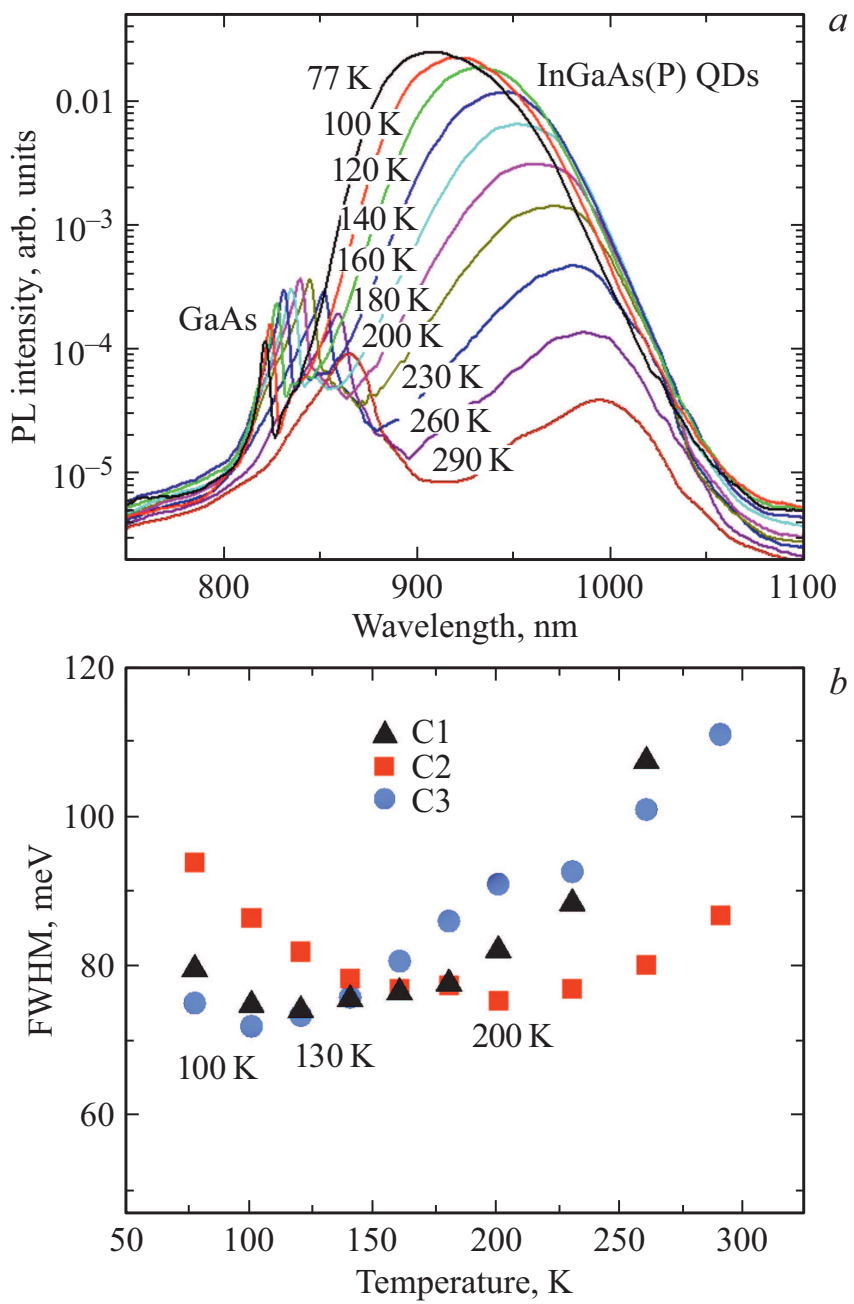

Рис. 3. Спектры ФЛ структуры С2, полученные при температурах $78-290 \mathrm{~K}(a)$ и зависимость полуширины линии ФЛ структур C1-C3 от температуры наблюдения $(b)$. 


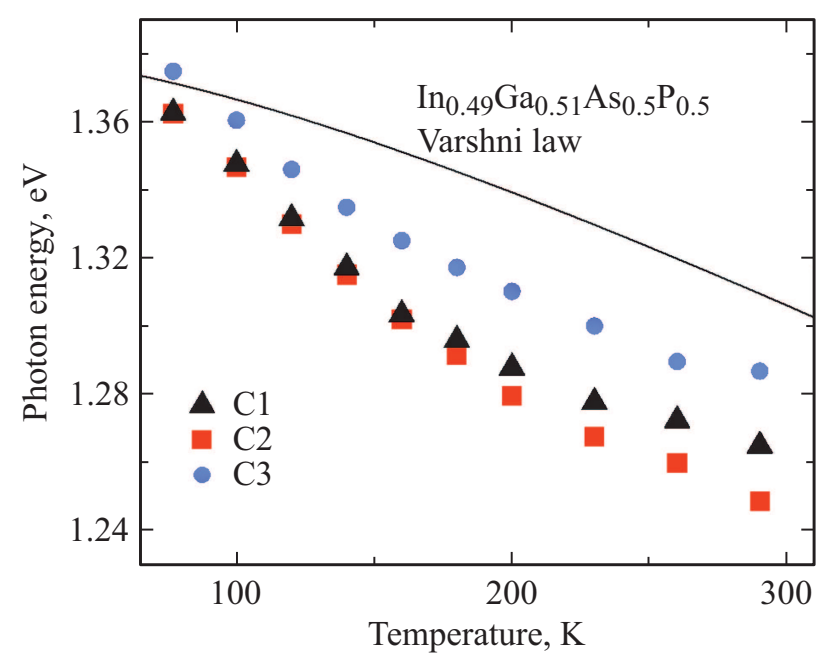

Рис. 4. Зависимость спектрального положения максимума ФЛ островков InGaPAs от температуры (символы) и ход зависимости Варшни для $\operatorname{In}_{0.49} \mathrm{Ga}_{0.51} \mathrm{P}_{0.5} \mathrm{As}_{0.5}$ (сплошная линия).

Наличие транспорта носителей между островками подтверждается ходом спектрального положения максимума ФЛ островков InGaPAs при повышении температуры (рис. 4). Полученный сдвиг при увеличении температуры не может быть описан с помощью выражения Варшни, которое используется для анализа температурного изменения ширины запрещенной зоны полупроводника (на рис. 4 для сравнения приведен ход зависимости Варшни для $\left.\mathrm{In}_{0.49} \mathrm{Ga}_{0.51} \mathrm{P}_{0.5} \mathrm{As}_{0.5}\right)$. На представленных зависимостях виден начальный участок резкого уменьшения энергии фотона, связанный с отмечавшимся ранее перезахватом носителей на более глубокие уровни. При переходе носителей в термализованное состояние при температурах выше $150 \mathrm{~K}$ ход зависимостей становится более плавным.

На спектрах возбуждения люминесценции (СВЛ), полученных при $10 \mathrm{~K}$, наблюдаются две линии поглощения, спектральное положение максимумов которых не зависит от длины волны детектирования (рис. 5). Первая линия соответствует поглощению в материале GaAs $(\sim 818 \mathrm{~nm})$, вторую линию с максимумом вблизи $838 \mathrm{~nm}$, мы связываем с поглощением в остаточном двумерном слое InGaPAs. Эти линии поглощения совпадают для всех трех образцов.

Кратковременный отжиг позволяет уменьшить количество точечных дефектов в структуре и тем самым уменьшить вклад безызлучательной рекомбинации. Далее был выполнен кратковременный отжиг образцов при температурах 600 и $650^{\circ} \mathrm{C}$ в течение $2 \mathrm{~min}$. Отжиг при $600^{\circ} \mathrm{C}$ привел к незначительному коротковолновому сдвигу максимума ФЛ островков InGaPAs, увеличению интенсивности ФЛ линии островков InGaPAs примерно в 3 раза для всех структур и существенному увеличению интенсивности линии GaAs (pис. $6, a, b$ ). Кроме того, для всех структур после отжига наблюдается уменьшение полуширины линии ФЛ во всем диапазоне температур наблюдения $78-300 \mathrm{~K}$, что говорит о формировании более однородного массива островков. Температура, при которой наблюдается переход к термализованному распределению носителей после отжига, составляет около $130 \mathrm{~K}$, значение полуширины линии ФЛ при комнатной температуре не превышает $75 \mathrm{meV}$ для всех трех структур. Увеличение температуры отжига до $650^{\circ} \mathrm{C}$ привело к исчезновению линии излучения островков InGaPAs/GaAs. При этом на спектрах возникает новая линия вблизи $930 \mathrm{~nm}$, которую мы связываем с остаточным двумерным слоем InGaPAs, ранее наблюдавшимся на спектрах возбуждения люминесценции (рис. 5), что, по всей видимости, означает, что при этой температуре происходит разложение материала островков.

Таким образом, в работе выполнены исследования спектров ФЛ трехмерных островков InGaPAs/GaAs, синтезированных при замещении фосфора на мышьяк в тонком слое $\mathrm{InGaP}$ (толщиной менее $3 \mathrm{~nm}$ ) с использованием подложек GaAs. При комнатной температуре массив островков InGaPAs/GaAs излучает в спектральном диапазоне 950-1000 nm. Несмотря на низкую поверхностную плотность островков, увеличение мощности оптической накачки вплоть до уровня, при котором существенную роль начинает играть излучение с состояний в GaAs, не приводит к насыщению роста интенсивности ФЛ островков. Исследования в диапазоне температур от 78-300 K свидетельствуют о неоднородности и высокой безызлучательной рекомбинации в структурах и необходимости применения методов, направленных на уменьшение структурных дефектов. Применение отжига структур позволило увеличить интенсивность ФЛ при комнатной температуре до $300 \%$ при незначительном коротковолновом сдвиге максимума ФЛ, а также улучшить однородность внутри массива островков. Полу-

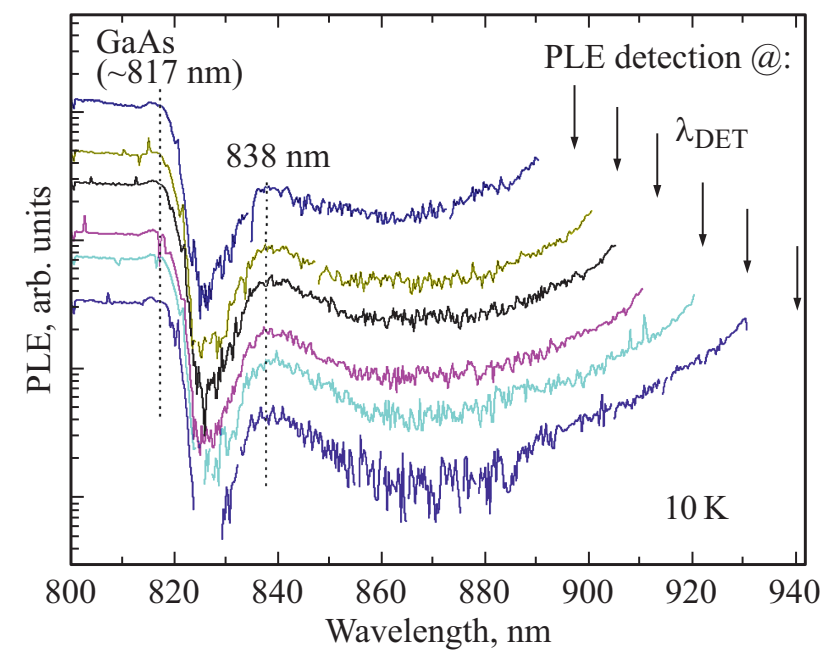

Рис. 5. Спектры возбуждения люминесценции, полученные при температуре $10 \mathrm{~K}$ структуры с островками InGaPAs. Спектры смещены по вертикали для удобства восприятия, длина волны детектирования указана стрелкой. 

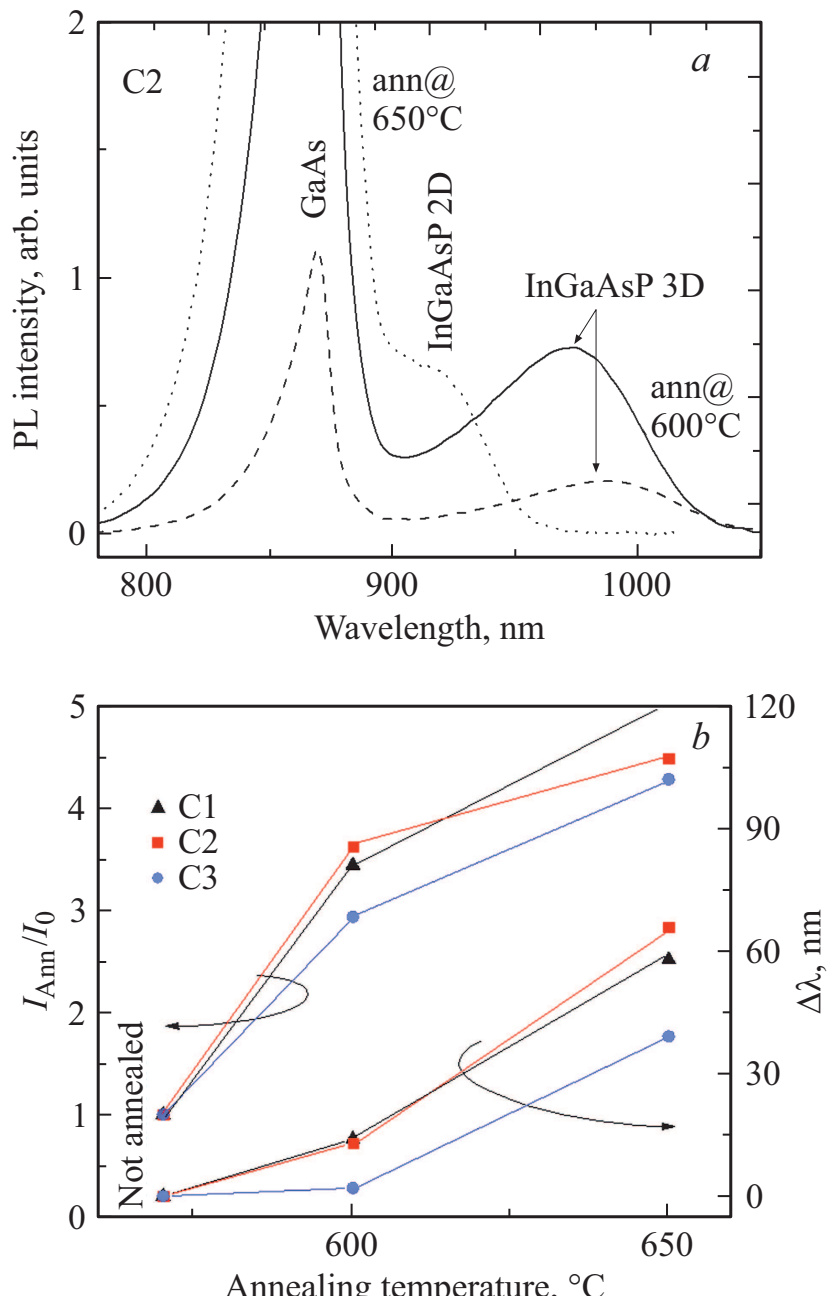

Рис. 6. Спектры ФЛ структуры С2, полученные при комнатной температуре до и после отжига при температурах 600 и $650^{\circ} \mathrm{C}(a)$. Относительное изменение интенсивности ФЛ и относительный сдвиг длины волны максимума излучения для линии островков InGaPAs $(b)$.

ченные результаты исследований массивов островков InGaPAs/GaAs свидетельствуют о возможности их использования для создания эффективных однофотонных излучателей.

\section{Финансирование работы}

Работа выполнена при поддержке Министерства науки и высшего образования Российской федерации, проект тематики научных исследований № 2019-1442.

\section{Конфликт интересов}

Авторы заявляют, что у них нет конфликта интересов.

\section{Список литературы}

[1] Michler P., Kiraz A., Becher C., Schoenfeld W.V., Petroff P.M., Zhang Lidong, Hu E., Imamoglu A. // Science. 2000. V. 290. Iss. 5500. P. 2282-2285.

[2] Ward M.B., Karimov O.Z., Unitt D., Yuan Z.L., See P., Gevaux D.G., Shields A.J., Atkinson P., Ritchie D. // Appl. Phys. Lett. 2005. V. 86. P. 201111.

[3] Zinoni C., Alloing B., Monat C., Zwiller V., Li L.H., Fiore A., Lunghi L., Gerardino A., de Riedmatten H., Zbinden $H$., Gisin N. // Appl. Phys. Lett. 2006. V. 88. P. 131102.

[4] Kok P., Munro W.J., Nemoto K., Ralph T.C., Dowling J.P., Milburn G.J. // Rev. Mod. Phys. 2007. V. 79. P. 135-174.

[5] Aspuru-Guzik A., Walther P. // Nat. Phys. 2012. V. 8. P. 285291.

[6] Giovannetti V., Lloyd S., Maccone L. // Nat. Photon. 2011. V. 5. P. 222-229.

[7] Cheung J.Y., Chunnilall C.J., Porrovecchio G., Smid M., Theocharous E. // J. Mod. Opt. 2007. V. 54. P. 373-396.

[8] Holewa P., Gawetczyk M., Ciostek C., Wyborski P., Kadkhodazadeh S., Semenova E., Syperek M. // Phys. Rev. B. 2020. V. 101. P. 195304.

[9] van Veldhoven P.J., Chauvin N., Fiore A., Nötzel R. // Appl. Phys. Lett. 2009. V. 95. P. 113110.

[10] Kobak J., Rousset J.-G., Rudniewski R., Janik E., Slupinski T., Kossacki P., Golnik A., Pacuski W. // J. Crystal Growth. 2013. V. 378. P. 274-277.

[11] Zhanguo Li, Yong Wang, Xin Gao, Guojun Liu, Yi Qu, Xiaohui Ma, Minghui You // IEEE. 2015 International Conference on Optoelectronics and Microelectronics (ICOM). 2015. P. 404-406.

[12] Koukourinkova S.D., Benamara M., Ware M.E., Wang Z.M., Salamo G.J. // Appl. Phys. Lett. 2016. V. 109. P. 123102.

[13] Гладышев А.Г., Бабичев А.В., Андрюшкин В.В., Денисов Д.В., Неведомский В.Н., Колодезный Е.С., Новиков И.И., Карачинский Л.Я., Егоров А.Ю. // ЖТФ. 2020. T. 90. C. 2139-2142. 